\title{
NOTES ON THE MORPHOLOGY OF THE STICKY "DOORKNOBS" OF LARVAE IN AN AUSTRALIAN HYPOPONERA SP. (FORMICIDAE; PONERINAE)
}

\author{
By Christian Peeters and Bert Hölldobler \\ Theodor Boveri Institut, \\ Lehrstuhl für Zoologie II der Universität, \\ Am Hubland, W-8700 Würzburg, Germany
}

\section{INTRODUCTION}

Larvae in many species of Ponerinae and in some other ant subfamilies are covered with fleshy "tubercles" (=pimple-like structures) which exhibit an astounding variety of shapes (see review in Wheeler and Wheeler 1976). Among these are the unusual "doorknob" tubercles which occur in a few ponerine genera. These specialized tubercles protrude conspicuously from the dorsal surface of various abdominal somites; they consist of a stout column bearing an inflated knob which is sticky at the end (Wheeler and Wheeler 1952). W. M. Wheeler (1900) suggested that they serve to attach the larvae to the walls or ceiling of the nest chambers, and this has been confirmed subsequently (see Wheeler and Wheeler 1952, Taylor 1967).

In the genus Hypoponera, pairs of doorknobs occur on the 4th and 5th abdominal somites; they are present in all known instars of all castes (Wheeler and Wheeler 1971). Taylor (1967) showed that the number of doorknobs is a useful generic character to differentiate Ponera (3-4 pairs) and Hypoponera (2 pairs).

In this paper we present a detailed morphological and histological study of the sticky doorknobs of larvae in an Australian Hypoponera sp.

\section{Material And Methods}

A colony of Hypoponera sp. was collected in Royal National Park, near Sydney, New South Wales, during January 1991. It consisted of one mated queen, 146 workers, and all stages of brood.

Manuscript received 3 March 1992 
This nest was found while collecting a colony of Rhytidoponera confusa from a rotting $\log$ in a temperate rain forest. Voucher specimens have been deposited in the Australian National Insect Collection (CSIRO Canberra) (sp. 8 A.N.I.C.) and the Museum of Comparative Zoology (Harvard University) (accession number OZB-5).

The ants were reared in a plaster-of-Paris nest and fed on freshly killed Drosophila.

For histological studies, larvae were fixed in alcoholic Bouin and stored in $75 \%$ ethanol. Prior to sectioning, they were embedded in Spurr's low viscosity medium. Serial sections $(0.5-2 \mu)$ were obtained using a histo-diamond knife and a Reichert-Jung microtome model 2050. The sections were attached to slides coated with egg-albumin and stained with Mallory's (1\% methylene blue and $1 \%$ azur II in $1 \%$ sodium borate) on a hotplate.

The SEM micrographs were taken with a Zeiss DSM940.

\section{RESULTS}

The doorknob tubercles are striking features on the dorsal surface of Hypoponera larvae. They measure approximately one tenth of the entire length of the larva and are clearly distinguishable from the numerous spire-like tubercles which cover the entire body (except head) of the larvae (Fig. 1). Our laboratory observations confirmed that the tip of the doorknobs are sticky and that these structures are used for attaching the larvae onto the walls of the nest chambers. The smaller spire-like tubercles are not sticky. In our observation nest, the larvae were usually not clustered, but were positioned singly on the walls where the workers provisioned them with prey pieces (Fig. 2). Only when the nest was disturbed (e.g., removing the red filter over the clear glass roof) were the larvae taken from the walls and transported to a darker corner of the nest. After the disturbance, the workers placed the larvae back onto the walls.

Inspection with the SEM did not reveal pores in the surface of the tip of the doorknobs. Their presence would have suggested that the doorknobs are equipped with exocrine glands. Thus, the origin of the sticky substance remained unclear. We therefore conducted a series of histological investigations which revealed that the doorknob tubercles as well as the spire-like tubercles are hemolymph- 


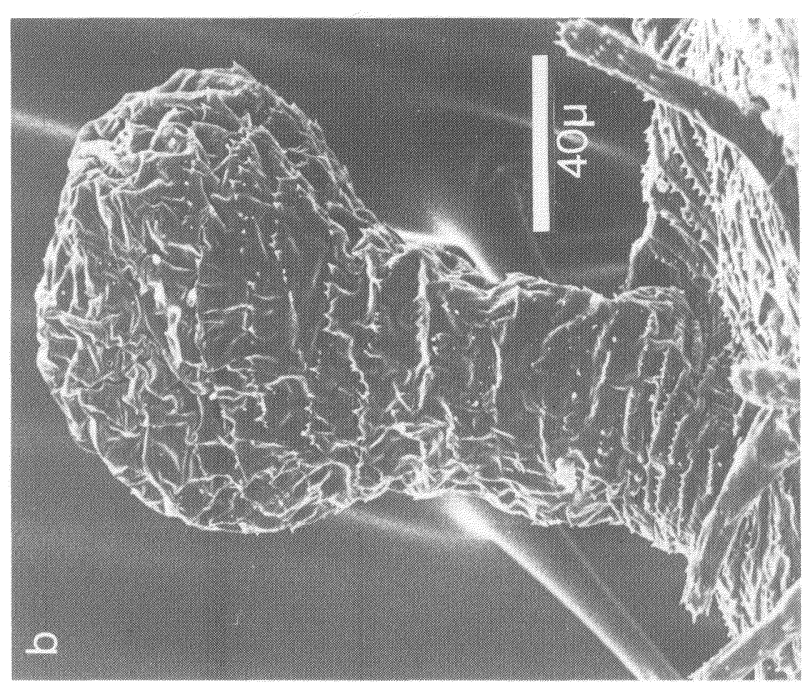

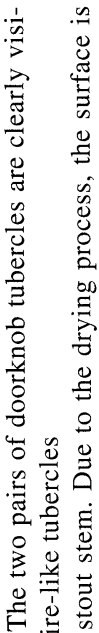

F.

in

के

ปั

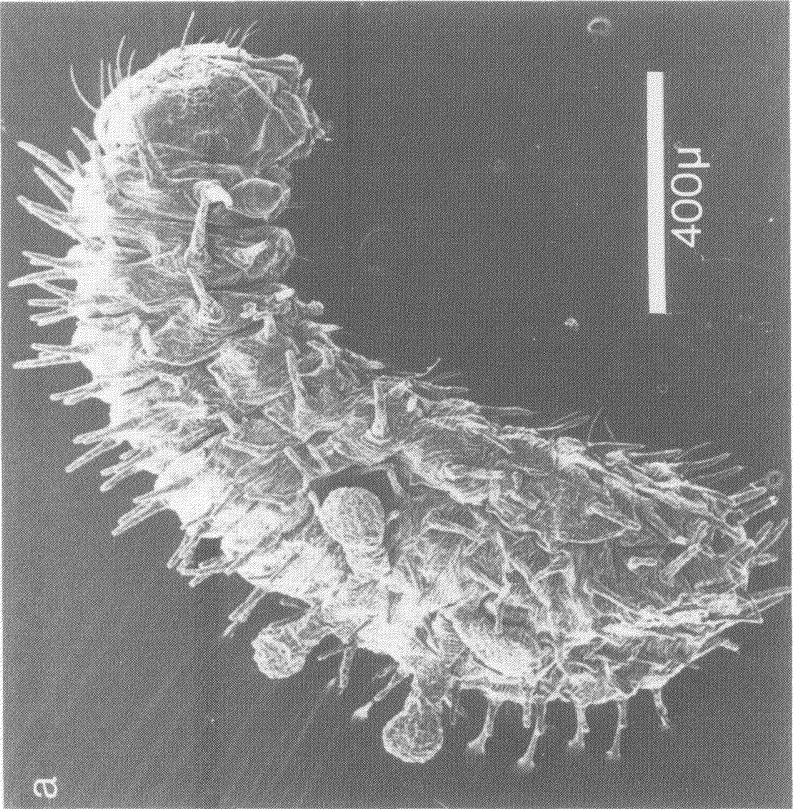

은

용.

$\Xi \frac{\infty}{\sigma} 0$

岁

운

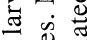

을

응

ส

bo.

政

的完

들 폴 웅

행

용

觉

$\exists \Xi \pi$

$\sum$ के

贸焉刍

बके

$-i \stackrel{ }{2}$

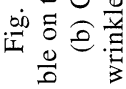



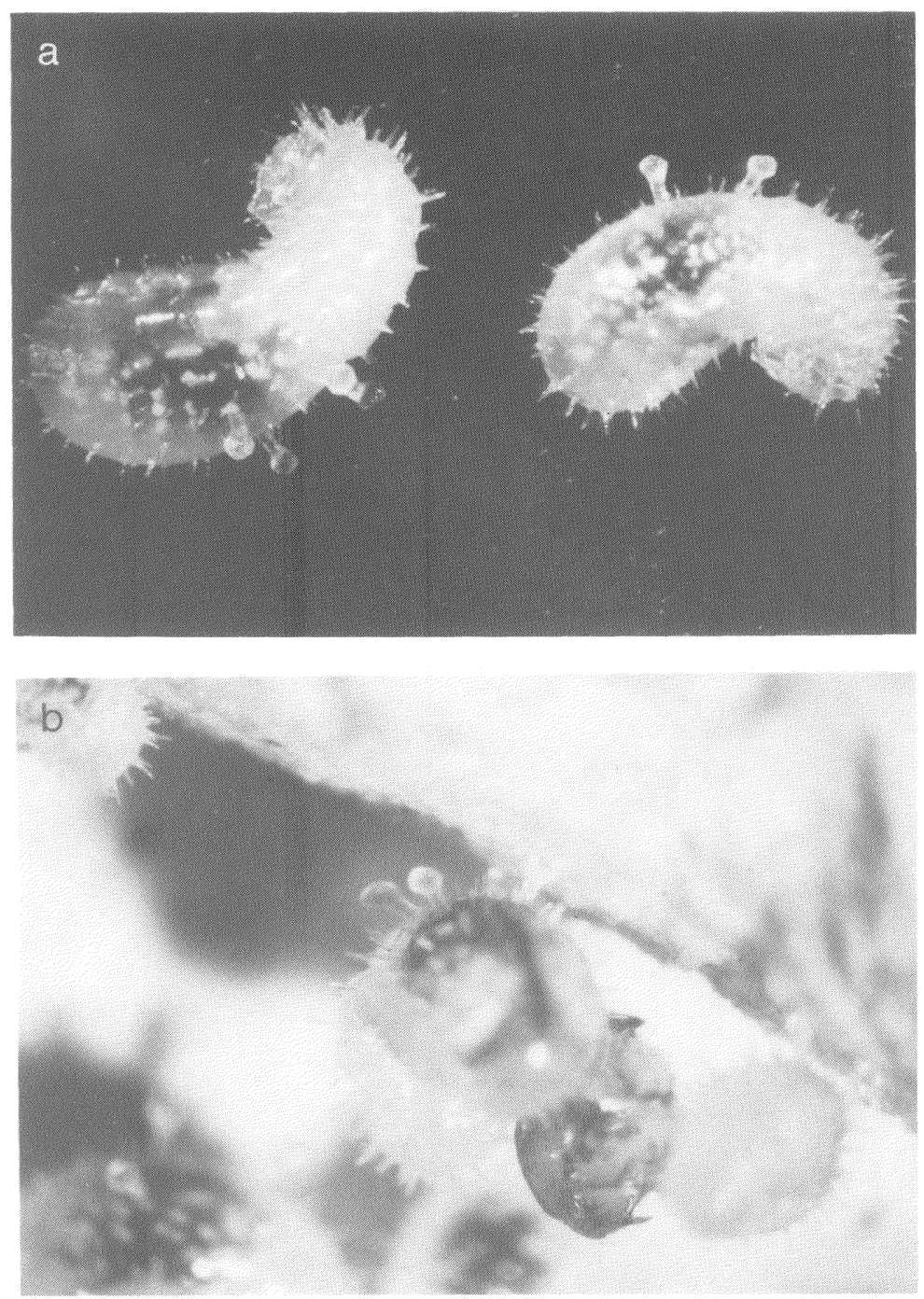

Fig. 2. (a) Two Hypoponera larvae photographed through a dissecting microscope, showing the natural appearance of the doorknob tubercles

(b) Larvae attached to the walls of the nest chambers. Both larvae are eating on a piece of prey which was placed there by workers. 
filled protrusions of the body surface. There are no muscles or innervation inside the doorknob tubercles. Thus, the slight movements of the doorknobs observed under the dissecting microscope are most likely the result of localized changes in hemolymph pressure. The epidermis and cuticle in the stem of both types of tubercles are not different from that elsewhere in the larvae. However, the inflated head of the doorknobs exhibits very different histological features. The epidermis is approximately five times thicker, and the epidermal cell nuclei are much larger than elsewhere in the larvae. Furthermore, the cuticle is remarkably different: it is three to four times thicker, consisting of multiple layers of endocuticle, and the exocuticle is extremely thin, so that it appears to be almost merged with the layers of endocuticle (Fig. 3).
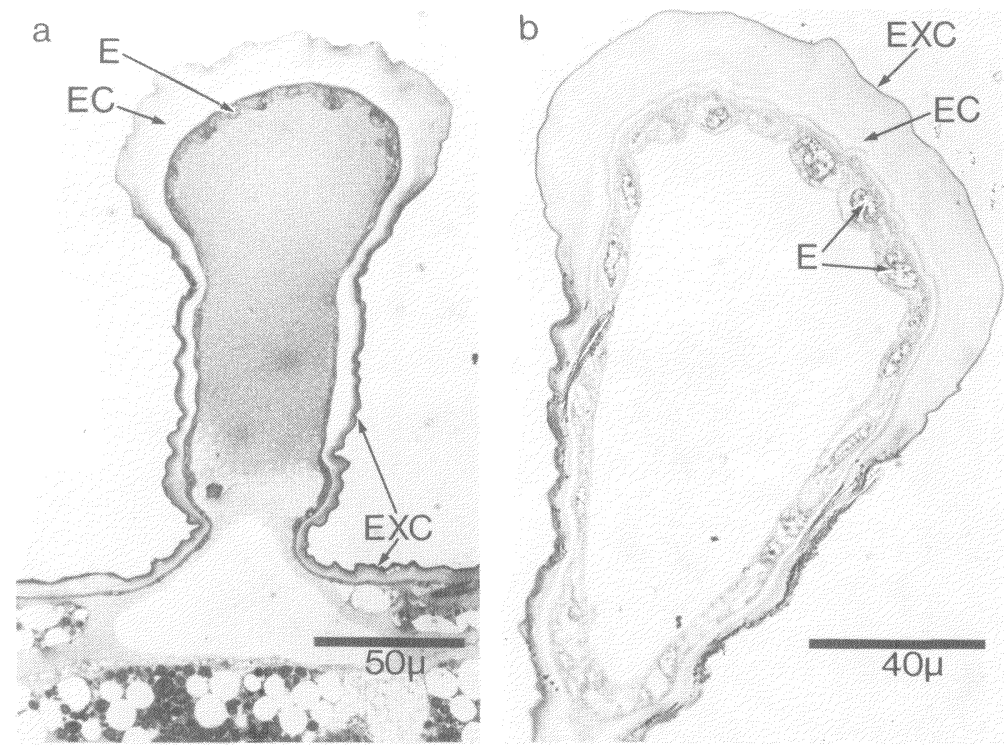

Fig. 3. (a) Histological section through a doorknob tubercle. Both the epidermis (E) and the endocuticle (EC) are thickened, while the exocuticle (EXC) thins out in the spherical tip of the doorknob structure

(b) Section through the tip of the doorknob tubercle, showing the glandular epithelium of the epidermis (E), the multi-layered endocuticle (EC) and the thinned-out exocuticle (EXC). 
Our histological findings show that there are no specialized exocrine glands which produce the sticky substance present on the surface of the inflated knob. It appears that the sticky material represents the soft and viscous cuticle which is secreted in layers by the very active glandular epithelium of the epidermis at the tip of the doorknob tubercles. We did not detect any specialized secretory features in the epidermis of the spire-like tubercles.

Some observations concerning the cocoons of Hypoponera sp. may also be of interest. Although all larvae started spinning a cocoon before they metamorphosed, the cocoon walls were usually so thin as to be transparent (Fig. 4). In other cases the thin cocoon was either partly or entirely removed, so that there were always naked unpigmented and pigmented pupae in the brood chambers. It appears that the workers eat away the cocoons once metamorphosis is complete.
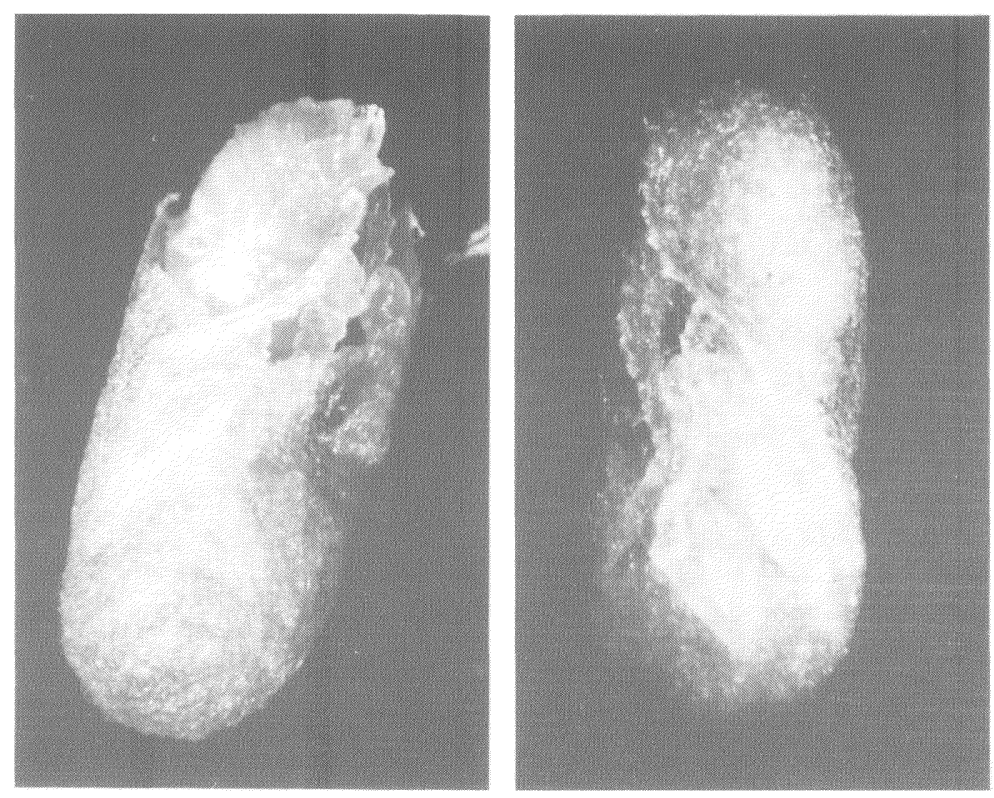

Fig. 4. Pupae of Hypoponera sp. The incomplete, transparent cocoon is seen clearly in both pictures. On the right, the cocoon is partly removed, after having been eaten away by workers. 


\section{DISCUSSION}

The occurrence of sticky "doorknobs" has been reported in several ponerine genera, i.e., Ponera, Hypoponera, Brachyponera, Cryptopone, Myopias (Wheeler and Wheeler 1971), and Probolomyrmex (Taylor 1965). Assuming that they serve exclusively for larval attachment, what may be the adaptive benefits? In the subfamily Ponerinae, larvae have tapered, flexible necks and strong mandibles, enabling them to bend and stretch to reach prey items placed near them. The fixation of larvae to walls may be an adaptation for giving freer play to the head and slender neck during feeding (Wheeler 1900). Alternatively, it keeps the body surface away from a humid substrate; rotten logs in rain forests sometimes get water-logged. There seem to be general benefits in attaching ant larvae onto walls or ceilings; it is achieved with anchor-tipped hairs in other groups (e.g., in Tetramorium, see Wheeler and Wheeler 1976).

The function of the numerous spire-like tubercles in Hypoponera larvae is not clear to us. They are not sticky and are certainly not involved in larval attachment. It has been suggested that these structures serve to protect against cannibalism from fellow larvae (Wheeler and Wheeler 1976). We have no evidence that such cannibalism occurs in Hypoponera sp.

Finally, we want to point out that the doorknob tubercles are very different from other tubercles which were recently investigated histologically. In some species of Platythyrea, larvae have one ventral tubercle which is often licked by workers. Villet et al. (1990) discovered that specialized epithelial cells at the base of this tubercle secrete a nutritive liquid. In contrast, the pair of tubercles found in larvae of Leptanilla japonica have no secretory function. They instead serve as a valve through which the queen can obtain hemolymph directly from the body cavity (Masuko 1989).

\section{SUMMARY}

The larvae of Hypoponera sp. from Australia have two pairs of fleshy "doorknob" tubercles on their dorsal surface. They have sticky ends and serve for attaching the larvae to the walls and ceiling of nest chambers. Our histological results indicate that the 
sticky surface is part of a soft, highly viscous cuticle at the tip of the doorknobs. It is secreted from a glandular epithelium of the epidermis, which is present only in this part of the larval body. The larvae also possess numerous spire-like tubercles which are not sticky and have no glandular epithelium.

\section{ACKNOWLEDGEMENTS}

We thank Malu Obermayer for the histology, Michael Melzer for scanning electron microscopy, and Jeanette Wheeler for help with bibliography. Supported by the Deutsche Forschungsgemeinschaft (Leibniz Prize to B. Hölldobler). We appreciate the permission received from the Australian Wildlife Protection Authority.

\section{Literature Cited}

MASUKO, K.

1989. Larval hemolymph feeding in the ant Leptanilla japonica by use of a specialized duct organ, the "larval hemolymph tap" (Hymenoptera: Formicidae). Behav. Ecol. Sociobiol. 24: 127-132.

TAYLOR, R. W.

1965. A monographic revision of the rare tropicopolitan ant genus Probolomyrmex Mayr. Trans. R. Entomol. Soc. Lond. 117: 345-365.

1967. A monographic revision of the ant genus Ponera Latreille. Pacific Insects Monograph 13, $112 \mathrm{pp}$.

Villet, M. H., S. A. Hanrahan, and C. Walther

1990. Larval structures associated with larva-to-adult trophallaxis in Platythyrea (Hymenoptera: Formicidae). Int. J. Insect Morphol. \& Embryol. 19: 243-256.

Wheeler, G. C. AND J. WheEler

1952. The ant larvae of the subfamily Ponerinae - Part II. Amer. Midland Nat. 48: 604-672.

1971. Ant larvae of the subfamily Ponerinae: second supplement. Proc. Ent. Soc. Amer. 64: 1197-1217.

1976. Ant larvae: review and synthesis. Ent. Soc. Washington Memoir 7, $108 \mathrm{pp}$.

WHEELER, W. M.

1900. The habits of Ponera and Stigmatomma. Biol. Bull. 2: 43-69. 

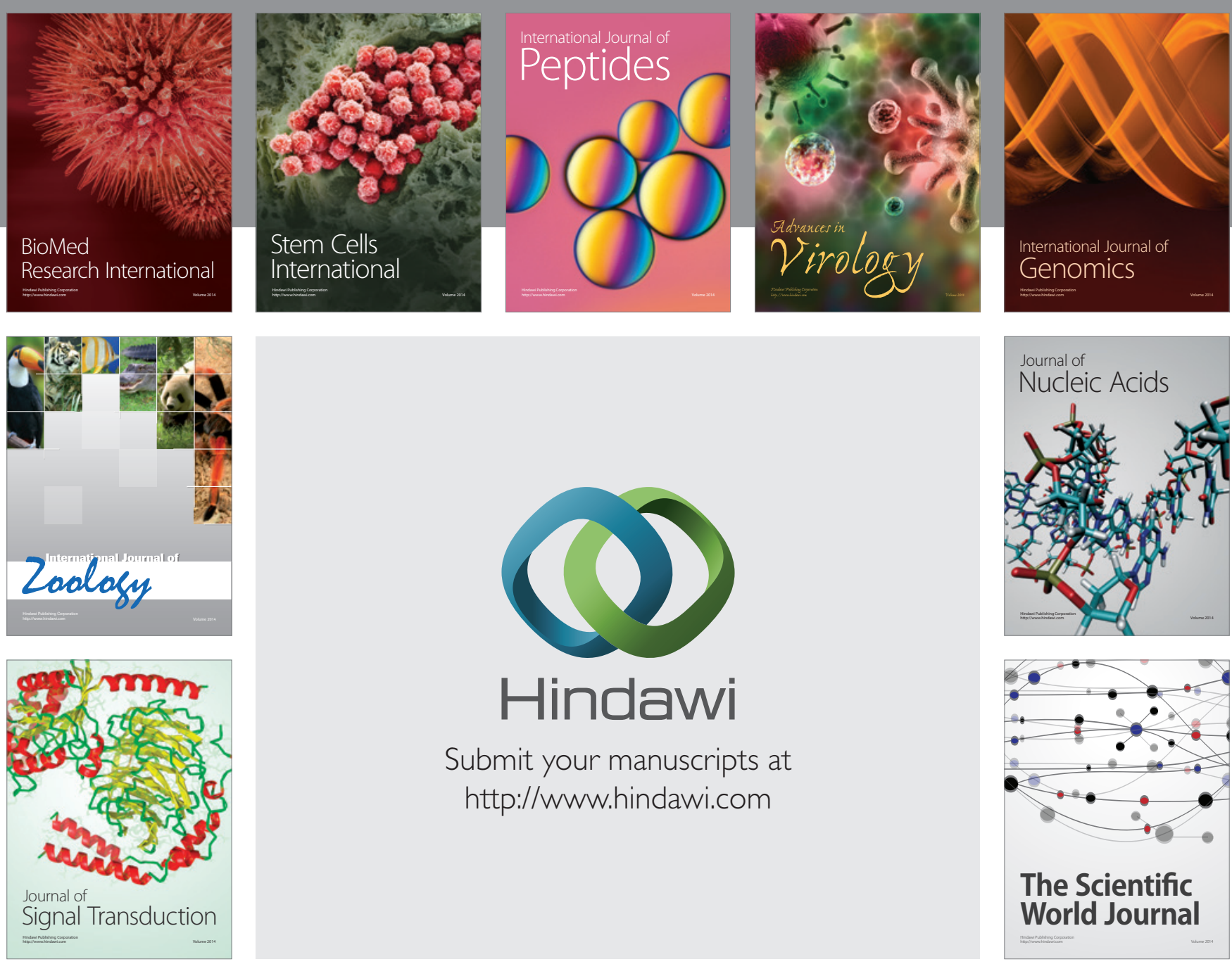

Submit your manuscripts at

http://www.hindawi.com
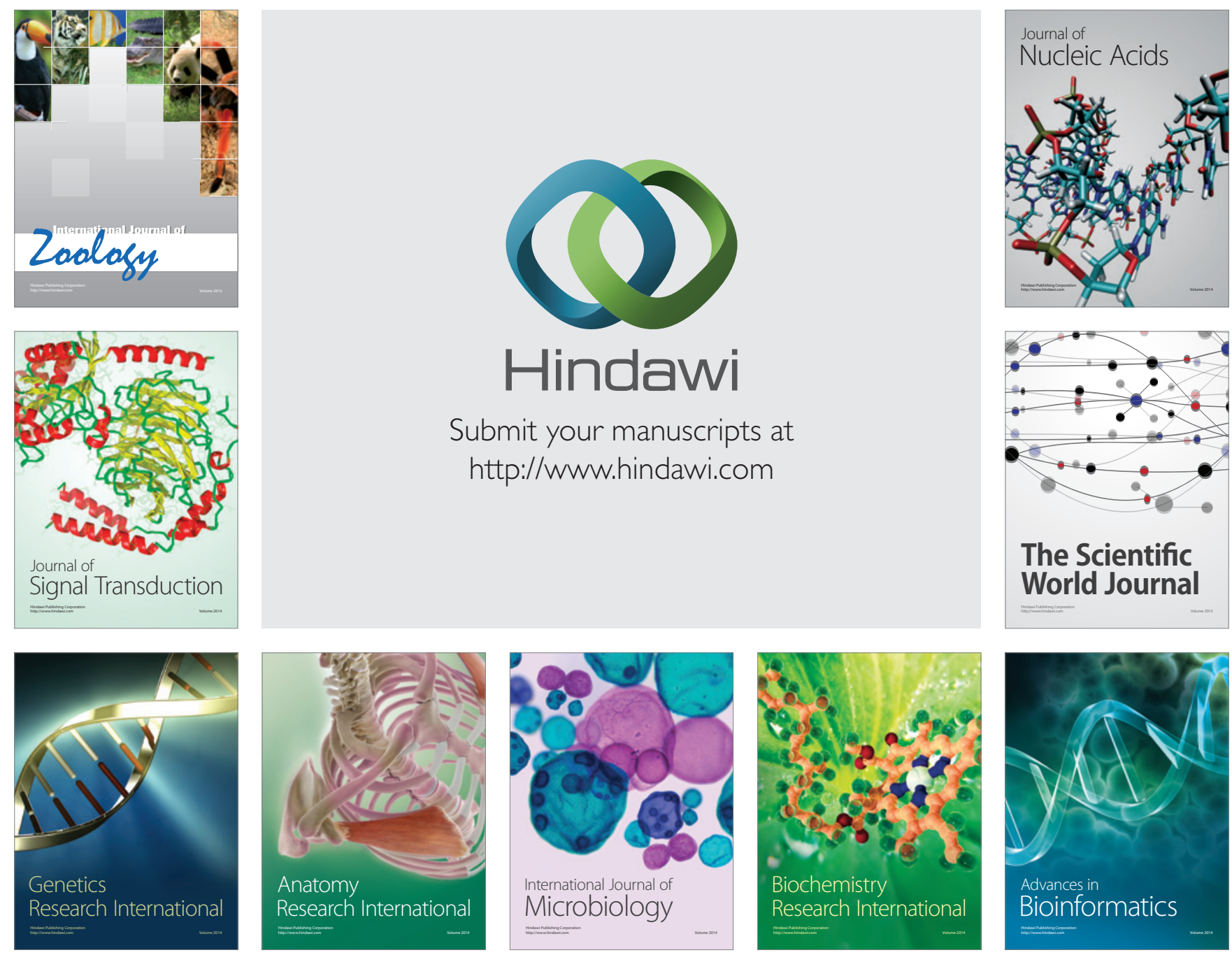

The Scientific World Journal
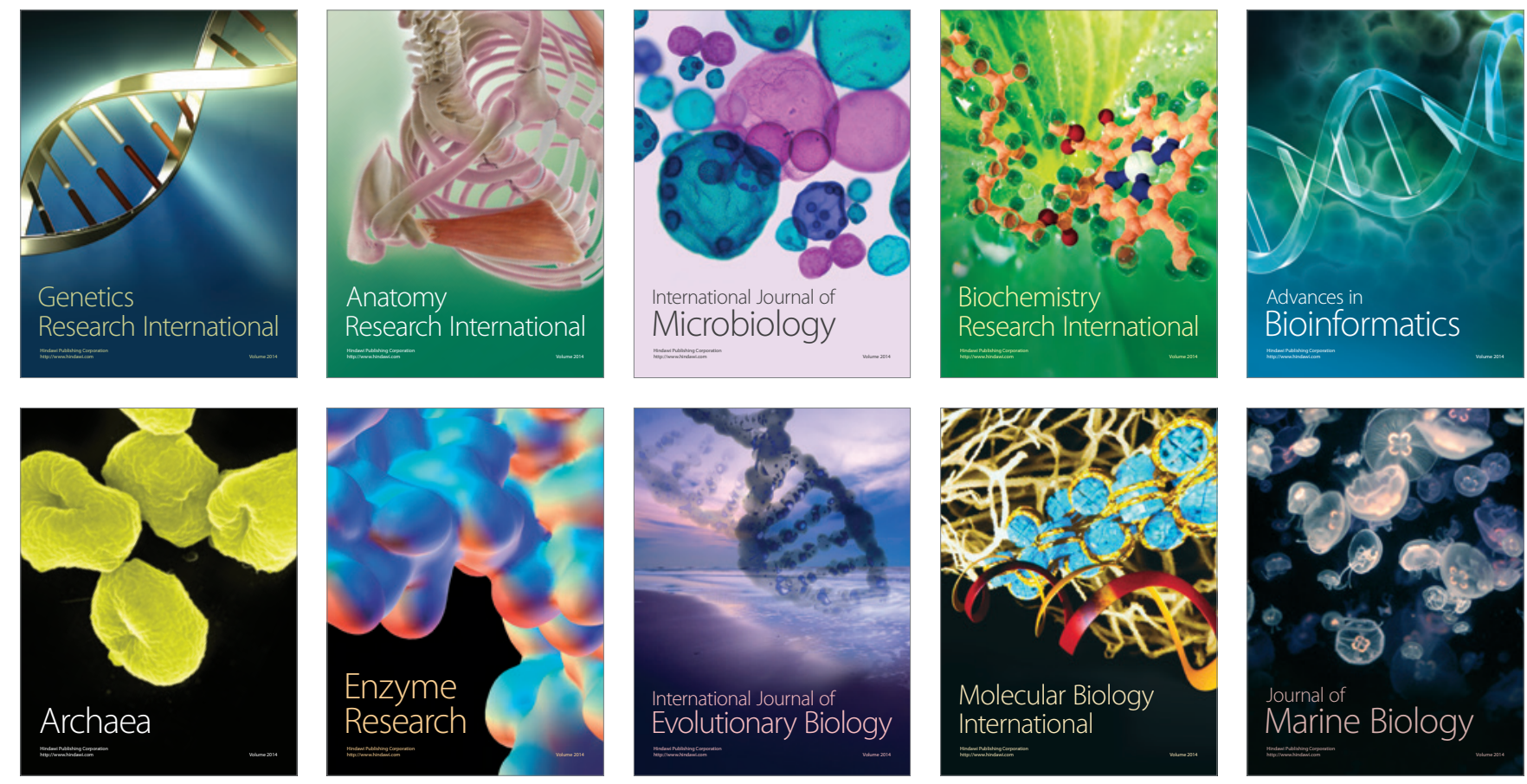